\title{
Gender difference regarding body image: a comparative study
}

\begin{abstract}
The objective of the present study was to determine gender difference in body dissatisfaction in married adults. The sample of the present research consisted of 200 married adults, 100 males and 100 females, selected from different organizations of Karachi following the purposive sampling technique. The age of the participants was from 22 years to 40 year (mean Age $=34.27 ; \mathrm{SD}=5.13$ ) with the minimum of 2 years and maximum of 20years of marriage. Their educational level was range from graduation and above. The entire sample belonged to middle socioeconomic status. After taking the consent from the participants, Multidimensional Body Self-Relations Questionnaire (MBSRQ) was administered. T-test was used to analyze the results. Significant gender differences were found on two variables of body image; fitness evaluation and body area satisfaction.
\end{abstract}

Keywords: body image, gender difference, married adult, MBSRQ
Volume 4 Issue 4 - 2016

\author{
Azra Shaheen,' Haresh Kumar, ${ }^{2}$ Wash Dev, ${ }^{3}$ \\ Om Parkash, ${ }^{4}$ Kelash Rai ${ }^{5}$ \\ 'Institute of Clinical Psychology, University of Karachi, Pakistan \\ ${ }^{2}$ Institute of Psychiatry, Baqai Medical University, Pakistan \\ ${ }^{3}$ Dow University of Health Sciences, Pakistan \\ ${ }^{4}$ Liaquat University of Medical and health Sciences, Pakistan \\ ${ }^{5}$ Ziauddin Medical College, Pakistan
}

Correspondence: Dr Haresh Kumar, Institute of Psychiatry, Baqai Medical University, Karachi, Pakistan, Tel +92333758990I, Email: hareshmakhija@gmail.com

Received: March 16,2016| Published: April 06, 2016

\section{Introduction}

The concept of body image has been the centre of attention for the past few decades. Every person has certain kind of view about his/ her physical appearance; some people consider themselves attractive, others consider themselves "unattractive". This attitude towards one's body is actually our body image; the perception, thinking and feelings about one's body and also how other perceives them. Body image is a subjective perception of one's body. Body image is world wide important factor in people's life, $74.4 \%$ women and $46 \%$ men with normal weight reported that most of the time they thought about their physical appearance; focus on appearance most of the time is a risk factor for the increase in negative body image. Negative body image is discrepancy between current and ideal body. It does not only relate to weight or shape of body but also included facial features, skin color, muscles tone and height. ${ }^{1,2}$

Women were the main subject matter regarding body-image studies in past researches but recent studies showed that men are equally affected by the ideal body-image set by society or culture but the men were more concerned about body-dissatisfaction in terms of feelings underweight rather than over-weight. ${ }^{1,3}$ Santos Silva et al., ${ }^{4}$ studied prevalence and associated factors with negative body image among adults they concluded that women had more negative body image then men as men considered themselves thinner than ideal and women considered heavier then their ideal. Negative body image was also found significantly correlated with depression, health problems, personal relationships and marital satisfaction.

Mostly literature indicated that females placed more importance to appearance and shape of their body that explained by feminine theorists that female body is objectified in society like as an object to be looked at. Therefore women body image depend on others views about her. This is supported by socio-cultural theorists that societal expectation and ideal of beauty encourage females to be attractive and invested more on physical appearance that can lead to negative body image and psychological distress. ${ }^{5}$ But other studies suggested that men are equally experienced socio-cultural pressure to achieve the muscular ideal due to this men are also at risk to developed negative body image and distress with body especially with their muscles size (chest, shoulders and stomach). Muscularity is considered as a sign of power so any man who fails to achieve ideal body can develop body image dissatisfaction. ${ }^{3,6}$

Diedrichs et al. $^{7}$ examined perception of men regarding their body image and comments of other's about their body shape. Results indicated that $85 \%$ men became more dissatisfied and negatively affect and engaged in negative ways in order to obtain perfect body shape.

The literature indicated the significance of body dissatisfaction is an important issue, needs to be investigated. Most of the studies have been conducted on women or college samples and ignored the men. Because of lack of researches in Pakistan regarding these variables we cannot signify the risk and protective factors of body image that how men and women are different regarding body image dissatisfaction. This study will help to provide significant information about these variables in context of Pakistani culture.

\section{Method}

\section{Participants}

The sample of the present study was taken from Karachi, Pakistan. A total sample of 200 married adults was selected purposively for the study. It was divided into two groups of 100 males and 100 females. The age range of the target group was 22 to 40 years (mean age 34 years; $\mathrm{SD}=5.13$ ) with minimum of 2 years and maximum of 20years of marriage. Their education level was from graduation and above. Their socioeconomic status was estimated on the basis of Household expenditure and survey (2001); they all belonged to middle socioeconomic class. 


\section{Measures}

Demographic Information Form: Demographic information form (Self developed) was included; the information related to the participant's marital status, duration of marriage, age, income, occupation, gender, education, family structure, socioeconomic status, type of marriage (Love/Arrange), weight and height.

Multidimensional Body Self-Relations Questionnaire (MBSRQ): The Multidimensional Body Self-Relations Questionnaire (MBSRQ) is a 34-item self-report inventory that evaluates several components of one's overall body-image. It is a validated questionnaire for the assessment of body image. The questionnaire has six sub-scales that assess an individual's investment in appearance through grooming behavior and satisfaction with their appearance, health, Illness, weight and fitness. The respondent is required to use Likert-type scale to indicate their level of agreement with the item where 1 (definitely disagree) to 5 (definitely agree). Cronbach alpha for the subscales are: Appearance evaluation and Appearance orientation; .88, Fitness evaluation; .77, Fitness orientation; .91, Body areas satisfaction; .77 and Subjective weight is .73 .

\section{Procedure}

The study was conducted after seeking approval from Ethical Review Committee of Board of Advance Studies and Research (BASR), University of Karachi, Pakistan. At the initial stage researchers met the authorities of different organizations located in Karachi to collect the data. Official permission was taken and purpose procedure of the study was explained, confidentiality ensured and informed consent was taken from the participants. The subject first completed the Demographic Information then Multidimensional Body Self-Relations Questionnaire (MBSRQ) and responses were scored according to the producer given in manuals. At the end of they were thanked for their cooperation.

\section{Statistical analysis}

Data was analyzed on SPSS version 21. Descriptive statistics of frequencies, percentages and means were calculated for the demographic variables of age, gender and weight, height and family structure, duration and type of marriage, birth order, education and occupation. Further t-test was employed to see gender difference on the variable of body image.

\section{Ethical consideration}

Present studies meet the ethical standards of APA guideline, principle of confidentiality, informed consent; permission (from authorities, participants, family of participant if it was seemed necessary and publishers) and right to with drawl from the study were followed by the researchers.

\section{Results}

Descriptive statistics of frequencies and percentages, mean and standard deviation were calculated for the demographic variables of age, gender and weight, height and family structure, duration and type of marriage, birth order, education and occupation are described in Table 1 through Table 2. Table 1 shows the descriptive statistics for the age, height, weight and duration of marriage. Table 3 describes the demographic variables of the sample and Table 2 describes the descriptive statistics of sub-scales of body image. The findings of ttest are presented in Table 4.
Table I It shows that mean age of the sample is 34.27 years, height is 5.44 , weight is 67.33 and mean duration of marriage is 2 years and 5 months

\begin{tabular}{llll}
\hline Variables & N & M & SD \\
\hline Age (years) & 200 & 34.27 & 5.13 \\
Height & 200 & 5.44 & 0.36 \\
Weight & 200 & 67.33 & 11.88 \\
Duration of marriage (years) & 200 & 2.5 & 1.26 \\
\hline
\end{tabular}

Mean age, height, weight and duration of marriage.

Table 2 Mean and Standard deviation of sub-scales of multidimensional body self-relations questionnaire and The Depression Anxiety Stress scale

\begin{tabular}{llll}
\hline Variables & N & M & SD \\
\hline $\begin{array}{l}\text { Multidimensional body self-relations } \\
\text { questionnaire sub-scales }\end{array}$ & & & \\
Appearance evaluation & 200 & 11.84 & 4.19 \\
Appearance orientation & 200 & 24.46 & 2.81 \\
Fitness evaluation & 200 & 7.05 & 1.91 \\
Fitness orientation & 200 & 24.08 & 3.23 \\
Subjective weight & 200 & 8.7 & 2.31 \\
Body areas satisfaction & 200 & 30.65 & 6.64 \\
\hline
\end{tabular}

Table 3 Descriptive Statistics of Demographic Information's of entire sample

\begin{tabular}{|c|c|c|}
\hline Variables & Frequency & Percentages \\
\hline \multicolumn{3}{|l|}{ Educational level } \\
\hline Graduation ( $14^{\text {th }}$ grade $)$ & 81 & $40.50 \%$ \\
\hline Masters (16 $6^{\text {th }}$ grade $)$ & 69 & $34.50 \%$ \\
\hline Post masters (Above $16^{\text {th }}$ grade) & 50 & $25 \%$ \\
\hline \multicolumn{3}{|l|}{ Family system } \\
\hline Nuclear & 93 & $46.50 \%$ \\
\hline Joint & 107 & $53.50 \%$ \\
\hline \multicolumn{3}{|l|}{ Birth order } \\
\hline$\left.\right|^{\text {st }}$ Born & 47 & $23.50 \%$ \\
\hline Middle born & 64 & $32 \%$ \\
\hline Last born & 17 & $8.50 \%$ \\
\hline \multicolumn{3}{|l|}{ Occupation } \\
\hline Govt-job & 81 & $40.50 \%$ \\
\hline Private job & 69 & $34.50 \%$ \\
\hline Non-working & 50 & $25 \%$ \\
\hline \multicolumn{3}{|l|}{ Type of marriage } \\
\hline Arrange & 144 & $72 \%$ \\
\hline Love & 56 & $28 \%$ \\
\hline
\end{tabular}

It shows most of the married adults has educational level $\left(14^{\text {th }}\right.$ grade, $\left.40 \%\right)$, Govt job (40.5\%), arrange marriage $(72 \%)$ and middle born $(32 \%)$, and they belong to both nuclear and joint family. 
Table 4 There is statistically significant difference on the body image variables (4) fitness evaluation and (6) body area satisfaction

\begin{tabular}{|c|c|c|c|c|c|}
\hline Variables & $\mathbf{M}$ & SD & $\mathbf{t}$ & df & $\mathbf{p}$ \\
\hline \multicolumn{6}{|c|}{ Appearance evaluation } \\
\hline Males & 11.55 & 2.29 & -1.781 & 197.987 & 0.076 \\
\hline Females & 12.13 & 2.31 & & & \\
\hline \multicolumn{6}{|c|}{ Appearance orientation } \\
\hline Males & 24.72 & 2.78 & 1.33 & 197.931 & 0.184 \\
\hline Females & 24.19 & 2.83 & & & \\
\hline \multicolumn{6}{|c|}{ Fitness evaluation } \\
\hline Males & 7.4 & 1.95 & 2.627 & $|96.88|$ & 0.009 \\
\hline Females & 6.7 & 1.81 & & & \\
\hline \multicolumn{6}{|c|}{ Fitness orientation } \\
\hline Males & 23.81 & 3.25 & -1.161 & 197.943 & 0.247 \\
\hline Females & 24.34 & 3.2 & & & \\
\hline \multicolumn{6}{|c|}{ Subjective weight } \\
\hline Males & 8.48 & 1.92 & -1.348 & 181.26 & 0.179 \\
\hline Females & 8.92 & 2.63 & & & \\
\hline \multicolumn{6}{|c|}{ Body area satisfaction } \\
\hline Males & 32.59 & 7.02 & 4.308 & 189.028 & 0 \\
\hline Females & 28.71 & 5.63 & & & \\
\hline
\end{tabular}

Mean, SD and t-tests of Males and Females on the six domains of Body Image. Note: $\mathrm{p}<.05^{*}$

\section{Discussion}

Physical attractiveness has a considerable social advantage therefore society placed much value on appearance which lead to adoption of society ideals thin for women and muscular body for men. In past studies the focus was females with reference of negative body image and ignored the males. Some studies conducted on males but their results were unclear. ${ }^{8}$

Therefore, the one purpose of this study was to examine the gender difference regarding body image. Results reveal discrepancy that there was not an overall gender difference in body image (Table 4). However, difference was found on sub-scales of body image (fitness evaluation and body area satisfaction). Men were slightly more concerned about their fitness and involved in activities to improve their physical fitness as compare to females while females were found more dissatisfied from their different body parts as compare to males. These results align with recent researches that body image is equally important issues for males too. But qualitatively men and women defined body image differently; generally females of all ages striving for thin body while men are about to divided into two groups one who want to loss weight and the other one to gain weight. ${ }^{9}$ With the same line concluded that men and women body image dissatisfaction was qualitatively different. Men were more disturbed to with specific body parts they desire the specific areas (chest, shoulders and stomach) to be larger. Men were less critical of their body size and shape but with the increase of BMI lead to dissatisfaction with body in both genders. ${ }^{10}$
Furthermore, several other researches indicated that body image affected by many variables such as culture, social status, gender and other personality difference but literature was lacking to explain all these variables and that how they affect body image. More recent studies have begun to explore these factors with relation to body image. Exposure of ideal body image threatens well-being of males and females. Now-a-days male body is also presented by media in objectified manner than has been in the past which increased body dissatisfaction in males. ${ }^{11}$ The previous studies indicated that concerns about body image were more common in women then men Cash, 1994 postulated that negative evaluation of body image and investment in appearance were more common in women rather than men but men were also equally concerned about change in weight and shape of body. Evaluation of body image and investment of appearance were predictors of negative body image in both genders. ${ }^{12}$

Results from the present study indicated there was not an overall gender difference in body image these findings lend to support the idea that negative body image may have greater gender specific manifestations than has been previously explored or my be gender serve as a buffer against the risk to develop negative body image. No gender differences in body image dissatisfaction were found thus suggesting that with the passage of time the level of dissatisfaction in men and women become parallel. ${ }^{8,9}$

Despite these findings, comparatively little studies have focused on the unique factors important for understanding male body image. Usually researches on women were used to conceptualize body image in both genders but it failed to adequately explain the body image in men. There is need to explore the important factor of muscularity with reference to male body image in order to better understand the gender difference.

\section{Conclusion}

The current study contributed to add knowledge in the literature regarding body-image, in the context of Pakistani culture. There is not overall gender difference regarding body image variables which showed that both genders equally experience negative body image. This study underlines the importance of being aware of the potential for sociocultural influences to adversely affect the populations.

\section{Acknowledgements}

None.

\section{Conflict of interest}

The author declares no conflict of interest.

\section{References}

1. Cash TF, Melnyk SE, Hrabosky JI. The assessment of body image investment: An extensive revision of the Appearance Schemas Inventory. Int J Eat Disord. 2004;35(3):305-316.

2. Grogen S. Body image: Understanding body dissatisfaction in men, women, and children. 2nd ed. USA: Routledge; 2008.

3. McCabe MP, Ricciardelli LA. Weight and shape concerns of boys and men. In: Thompson JK, editor. Handbook of eating disorders and obesity. USA: Wiley-Sons; 2004. p. 606-634.

4. Santos Silva DA, Nahas MV, de Sousa TF, et al. Prevalence and associated factors with body image dissatisfaction among adults in southern Brazil: A population- based study. Body Image. 2011;8(4):427-431. 
5. Iqbal N, Shahnawaz M, Alam A. Educational and gender differences in body image and depression among students. Journal of the Indian Academy of Applied Psychology. 2006;32(3):269-272.

6. Esnaola I, Rodriguez A, Goni A. Body dissatisfaction and perceived sociocultural pressures; gender and age differences. Salud Mental. 2010;33:21-29.

7. Diedrichs PC, Lee C. GI Joe or Average Joe? The impact of average-size and muscular male fashion models on men's and women's body image and advertisement effectiveness. Body Image. 2010;7(3):218-226.

8. Wong L, Say Y. Gender difference in body image perception among northern Malaysian tertiary students. British Journal of medicine \& medical research. 2013;3(3):727-747.
9. Benuto L, Haboush A, Jones-Forrester S. Compensatory efforts for body dissatisfaction; some gender and ethnic differences. The new school Psychology Bulletin. 2007;5(2):19-25.

10. Gillen MM, Lefkowitz ES. Gender and racial differences in body image development among college students. Body Image. 2012;9(1):126-130.

11. Bergeron DP. The relationship between body image dissatisfaction and Psychological health: An exploration of body image in young adult men. The Ohio State University; 2007. 126 p.

12. Yahia N, El-Ghazale H, Achkar A, et al. Dieting practices and body image perception Lebanese university students. Asia Pac J Clin Nutr. 2011;20(1):21-28. 